\title{
Preparation of Polypropylene/Bentonite Composites of Enhanced Thermal and Mechanical Properties using L-leucine and Stearic Acid as Coupling Agents
}

\author{
Nadia Mohammedi \\ Department of Process Engineering \\ Ferhat Abbas Setif University 1 \\ Sétif, Algeria \\ chimiebatna2016@gmail.com
}

\author{
Fouzia Zoukrami \\ Emerging Materials Research Unit \\ Ferhat Abbas Setif University 1 \\ Sétif, Algeria \\ fzoukrami@univ-setif.dz
}

\author{
Nacereddine Haddaoui \\ Department of Process Engineering \\ Ferhat Abbas Setif University 1 \\ Sétif, Algeria \\ n_haddaoui@univ-setif.dz
}

\begin{abstract}
The compatibilization of raw bentonite (bent) with a polymer matrix of polypropylene (PP) can improve the performance of the material in terms of thermal and mechanical properties. In this study, two kinds of untreated bentonite, bentonite-Maghnia (bent-m) and bentonite-Mostaganem (bent$\mathrm{M})$, that differ in the proportion of $\mathrm{Al}_{2} \mathrm{O}_{3}$ and in the particle size distribution were coupled to typical maleic anhydride grafted polypropylene PP-MA. Stearic Acid (SA) and L-leucine Amino Acid (AA) were selected as new coupling modifiers at a 5/5 ratio of bentonite/coupling agent. All PP/bent composites were prepared by melt mixing at $190^{\circ} \mathrm{C}$. Morphological observation revealed a good dispersion of bentonite into the $P P$ matrix in the presence of AA, SA, and PP-MA. Mechanical properties showed an increase in stiffness as bent-m or bent-M were associated with AA. For instance, PP/bent-m/AA composite underwent an improvement of about $13 \%$ in Young's modulus as compared to neat PP. On the other hand, the addition of SA into bent-m maintained stiffness and tensile strength at an acceptable level. An increase of around $40^{\circ} \mathrm{C}$ and $37 \%$ in the decomposition temperature and elongation at break was respectively observed for the PP/bent-m/SA composite. All coupled composites showed high degradation temperatures.
\end{abstract}

Keywords-bentonite; surfactant; coupling agent; mechanical properties; layered composite

\section{INTRODUCTION}

Recently, the development and characterization of polymer/clay nanocomposites has been the subject of increasing interest because these systems habitually show significant improvement in thermal, mechanical, and barrier properties when compared with virgin polymers or conventional micro or macro composites for the same amount of filler. Usually, the improvement is due to the high surface area of layered silicates which is more than $700 \mathrm{~m}^{2} / \mathrm{g}$, its aspect ratio of about 50-200, in addition to the possible exfoliation or intercalation and good dispersion of clay intopolymer matrix $[1,2]$. At the melt state, the dispersion of clay particles into polyolefin matrix depends on several factors such as processing time, cationic surfactant modified clay, processing method, and interface modifiers. Recent studies have reported the effects of these factors on the properties and clay basal spacing of $\mathrm{PP} / \mathrm{EVA} /$ nanoclay composites [3], PVC/bentonite organoclay system [4] and PP/clay composites [5, 6].

Polypropylene (PP) is selected in polymer composite or nanocomposite systems because it is widely used in engineering materials, electronic cases and interior decoration for its excellent insulation properties, low cost, ease of processing [7], and recyclability [8]. To enhance the thermal stability and other properties of PP, researchers have tried to use nanotechnology [9]. On the other hand, bentonite, which is a geological material, is often used as filler in polymer matrix. Bentonite has a structure that generally consists of two tetrahedral sheets (silicon/oxygen) separated by an octahedral sheet (aluminum/oxygen/hydroxyl) [10,11]. The ions with positive charges on the clay surface can be adsorbed onto the bentonite structure due to the interaction between the negative and positive charges. Bentonite is used in diverse branches of industry for the fabrication of several ceramic products mainly due to its rheological properties. Also, it is used as a component in dyes, pharmaceuticals, paper [12-15], and in polymer composites [16]. The industrial and environmental applications of bentonite have showed an increase of interest in recent years [13]. For example, in [17], two different bentonite/PP composites were synthesized, with and without pore-enlarging treatment. These granular composite adsorbents were effective in eliminating $\mathrm{Pb}^{2+}$ in aqueous solutions. 
Moreover, the preparation of $\mathrm{PP} /$ bentonite micro or nanocomposites is not straightforward due to the poor interaction between the non-polar polymers like PP and polar bentonite. Therefore, by adding PP-MA to the system as a coupling agent, the improvement in the interfacial adhesion is possible [8]. PP-MA is often used with a large number of polyolefin materials $[12,15]$. Authors in [18] reported that for $\mathrm{PP} /$ modified montmorillonite (MMT) and PP/treated sodium bentonite, diethyl maleic grafted PP (PP-DEM) compatibilizer has lower polarity compared to maleic anhydride grafted polypropylene (PP-MA). They concluded that clay and matrix modification are the key factors and must be carefully and properly used to get the appropriate properties in the non-polar polymer based nanocomposites [19]. The ion exchange treatment of layered silicate is often influenced by the length of the alkyl chain, and the quality of multiple interactions [20, 21]. Authors in [22] indicated that the exfoliated nanocomposite based cloisite 15A compatibilized with acrylic acid grafted high density polyethylene (HDPE-AA) and maleic anhydride grafted high density polyethylene (HDPE-MA) displayed a higher level of clay dispersion. However, HDPE compatibilized with ethylene-acrylic acid copolymer (EAA) leads to poor dispersion due to its immiscibility with the HDPE matrix. Recently, authors in [23] confirmed that the composites containing modified bentonite in presence of stearic acid used as interface modifier induce a better dispersion of the filler, a decrease in viscosity and an increase in elongation at break of the composites based on PP matrix. Also, authors in [24] established that stearic acid favored the dispersion of PP/MMT nanocomposites when used as interface modifier and clay surface treatment. The samples exhibited crystallization temperatures comparable to pure PP, with a good dispersion. In [25], the authors synthesized L-leucine micro/nanocrystals and showed that these samples have a large potential in pharmaceutical applications as dispersibility improvers. This coating design concept can also be used for diverse active pharmaceutical ingredients.

In our study, two bentonites, bentonite-Maghnia (bent-m) and bentonite-Mostaganem (bent-M) from two different regions of Algeria were incorporated into a PP matrix. The traditional reactive maleic anhydride-grafted polypropylene PP-MA was used as a coupling agent to produce, via direct melt intercalation, PP/bent-m/PP-MA and PP/bent-M/PP-MA composites. Also, PP/bent-m/SA, PP/bent-M/SA, PP/bent$\mathrm{m} / \mathrm{AA}$, and PP/bent-M/AA composites were obtained using stearic acid, SA, and L-leucine amino acid AA, respectively as coupling agents. Large utilization of PP-based layered composites is possible if a more effective or a less expensive compatibilizer is available. It is important to point out that stearic acid has a low cost and only small amounts are required. On the other hand, its hydrocarbon end is compatible with PP [24]. The purpose of this study is the use of raw bentonites, which have not previously been subjected to chemical treatments to improve their compatibility, as these treatments usually involve the use of chemicals difficult to eliminate [26]. Stearic acid and L-leucine have been incorporated directly in $\mathrm{PP} /$ bent composites at the melt state. The preparation, characterization, and mechanical properties of the prepared materials are reported here. Some formulations exhibited significant improvements in the mechanical properties and degradation temperature when compared to pure PP. To the best of our knowledge, there are no previous reports of the use of this amino acid in improving the mechanical and thermal properties of $\mathrm{PP}$ /natural microbentonite composites obtained in molten state and the use of stearic acid as interface modifier for this system when it is introduced directly with polymer matrix and filler in internal mixer has not been reported.

\section{EXPERIMENTAL PART}

\section{A. Materials}

The PP used in this study (homopolymerAdstif HA740N) was supplied by Lyon dellBasell industries with Melt Flow Index (MFI) of $12 \mathrm{~g} / 10 \mathrm{~min}$ and density of $0.9 \mathrm{~g} / \mathrm{cm}^{3}$. The clays used as reinforcement filler are natural bentonites from Algeria, supplied by BENTAL Society: bentonite of Maghnia (bent-m) with average diameter of $10.7 \mu \mathrm{m}, \% \mathrm{Al}_{2} \mathrm{O}_{3}$ of 17.79 , and cation-exchange capacity (CEC) of $65 \mathrm{meq} / 100 \mathrm{~g}$ [27], and bentonite of Mostaganem (bent-M) with average diameter of $24.8 \mu \mathrm{m}, \% \mathrm{Al}_{2} \mathrm{O}_{3}$ of 13.78 , and CEC of $48 \mathrm{meq} / 100 \mathrm{~g}$ [28]. On the other hand, the ratio of $\mathrm{SiO}_{2} / \mathrm{Al}_{2} \mathrm{O}_{3}$ in bent-m is 3.62 and in bent-M 4.49, which classifies it as Si-bentonite. Three different coupling agents were used, maleic anhydride-grafted polypropylene PP-MA, which was provided by CromptonUniroyal Chemical (Polybond3200), with MFI of 90$120 \mathrm{~g} / 10 \mathrm{~min}$ and a density of $0.91 \mathrm{~g} / \mathrm{cm}^{3}$, stearic acid (SA), supplied by Henkel (Germany), and L-Leucine $\mathrm{C}_{6} \mathrm{H}_{13} \mathrm{NO}_{2}$ interface amino acid (AA), purchased from MERCK. All the materials were used as received.

\section{B. Elemental Analysis of Raw Bentonite}

The elemental analysis of raw bentonite shows that the bent-m has higher alumina content $\left(\mathrm{Al}_{2} \mathrm{O}_{3}=17.79\right)$ than bent-M $\left(\mathrm{Al}_{2} \mathrm{O}_{3}=13.78\right)$, however the iron content of bent- $\mathrm{M}$ is more. The stoichiometric analysis results are:

bent-m (\%mass): $\mathrm{SiO}_{2}-64.44, \mathrm{Al}_{2} \mathrm{O}_{3}-17.79, \mathrm{CaO}-3.16$, $\mathrm{Fe}_{2} \mathrm{O}_{3}-2.84, \mathrm{MgO}-5.48, \mathrm{Na}_{2} \mathrm{O}-1.12, \mathrm{~K}_{2} \mathrm{O}-1.27, \mathrm{SO}_{3}-0.02$.

bent-M (\%mass): $\mathrm{SiO}_{2}-61.89, \mathrm{Al}_{2} \mathrm{O}_{3}-13.78, \mathrm{CaO}-7.06$, $\mathrm{Fe}_{2} \mathrm{O}_{3}-3.66, \mathrm{MgO}-3.12, \mathrm{Na}_{2} \mathrm{O}-0.92, \mathrm{~K}_{2} \mathrm{O}-1.69, \mathrm{SO}_{3}-0.14$.

\section{Preparation of PP/Bentonite Composites}

PP-MA pellets were pre-mixed in a bag with bentonite (bent-m/PP-MA) at 5:5 weight ratio as well as bent-m/AA, bent-M/AA, bent-m/SA, and bent-M/SA and then, with PP at $5 \%$ wt. All the coumpounds were dried in a vaccum oven for $24 \mathrm{~h}$ at $80^{\circ} \mathrm{C}$, except SA and were melted in a Brabender mixing chamber (Plasti-corder EC), which was pre-heated at $190^{\circ} \mathrm{C}$. The rotor speed was set at $40 \mathrm{rpm}$, and the time of mixing was fixed at $20 \mathrm{~min}$. Mixing times between 8 and $50 \mathrm{~min}$ and rotating speeds between 40 and 150rpm have been used in different laboratory polymer mixers [29-33]. The material was withdrawn from the mixer chamber with a spatula, compressed between hot plates at $190^{\circ} \mathrm{C}$ in a Collin press, under 100bar, followed by cold pressing at $20^{\circ} \mathrm{C}$.

\section{Characterization}

\section{1) $X R D$}


X-Ray Diffraction (XRD) spectra were recorded using a Brucker D8 Advance A25 diffractometer with a copper laser and a SSD160 TM detector. Ni-filtered $\mathrm{CuK \alpha}$ radiation (wavelength of $0.1542 \mathrm{~nm}$ ) was produced at $40 \mathrm{kV}$ and $25 \mathrm{~mA}$. Scattered radiation was detected at the angular range of $(2 \theta) 0$ $45^{\circ}$ with a step of $0.02^{\circ}$.

\section{2) FTIR}

The different composites studied were analyzed by Fourier Transform Infrared Spectroscopy (FTIR) in the transmission mode using $\mathrm{KBr}$ pellets for the powdered sample and films prepared by compression-molded for PP/bentonite composites. The spectra were recorded on a Perkin Elmer Spectrum 1000 spectrometer at a resolution of $4 \mathrm{~cm}^{-1}$ in the range of 4000 to $400 \mathrm{~cm}^{-1}$.

\section{3) $S E M$}

For Scanning Electron Microscopy (SEM) micrographs, several acquisitions of images were performed on the surface of the sample in several zones and with different magnifications from 500x to 5000x in SEM-EDXQuanta 250 tungsten filament equipment.

\section{4) $\mathrm{DSC}$}

The melting points $\left(T_{m}\right)$ of the PP composites and the virgin PP were analyzed with a Differential Scanning Calorimeter (DSC) Q 2000 thermal analyser. The samples were heated from $-50^{\circ} \mathrm{C}$ to $200^{\circ} \mathrm{C}$ at the rate of $20^{\circ} \mathrm{C} / \mathrm{min}$ under an inert atmosphere of nitrogen $(50 \mathrm{ml} / \mathrm{min})$, after decreasing the temperature from room temperature to $-50^{\circ} \mathrm{C}$. Then, the samples were heated up to $200^{\circ} \mathrm{C}$ and were maintained at this temperature for $5 \mathrm{~min}$. Consecutive to the heating process, samples were cooled down to $25^{\circ} \mathrm{C}$, and after that, new successive heating and cooling runs were performed. The crystallinity percentage $\left(X_{c}\right)$ was calculated with:

$$
\times_{C}=\frac{\left(\Delta H_{m}\right)}{\emptyset\left(\Delta \mathrm{H}_{\mathrm{o}}\right)} \times 100
$$

where $\Delta H_{m}$ is the measured heat of melting per gram of polymer during the second heating scan, $\Delta H_{0}(207.1 \mathrm{~J} / \mathrm{g})$ is the theoretical heat of crystallization of $100 \%$ crystalline isotactic polypropylene [34], and $\varnothing$ is the weight fraction of PP in the composite. Thermal analysis was performed in a Q2000 TA instrument. The samples $( \pm 10 \mathrm{mg})$ were weighed to $0.002 \mathrm{mg}$ with an electronic balance (Perkin-Elmer AD4). The samples were heated from $25^{\circ} \mathrm{C}$ to $900^{\circ} \mathrm{C}$ at a heating rate of $20^{\circ} \mathrm{C} / \mathrm{min}$ in air. All the samples were previously dried at $80^{\circ} \mathrm{C}$ for $24 \mathrm{~h}$.

\section{5) Mechanical Properties}

Tensile tests were carried out according to UNE-ENN ISO 527-1 and 527-2 with an Instron Model 5500R60025 apparatus. One $\mathrm{mm}$ thick specimens were cut from the sheets with a Wallace die cutter. Across-head speed of $10 \mathrm{~mm} / \mathrm{min}$ was used.

\section{RESULTS AND DISCUSSIONS}

\section{A. Processability (Torque Value)}

Figures 1 and 2 show the processing torque during the mixing of $\mathrm{PP} / \mathrm{bent}$ composites. It was observed that the addition of $5 \%$ of AA and PP-MA to the polymer matrix loaded with $5 \%$ bent- $m$ increased the torque values of the systems (31N.m, 25N.m), suggesting that the composites required more severe processing conditions in its presence. In contrast, $5 \%$ of SA conducted $\mathrm{PP} /$ bent-m system to processing torque reduction (15N.m) and improved flow properties.

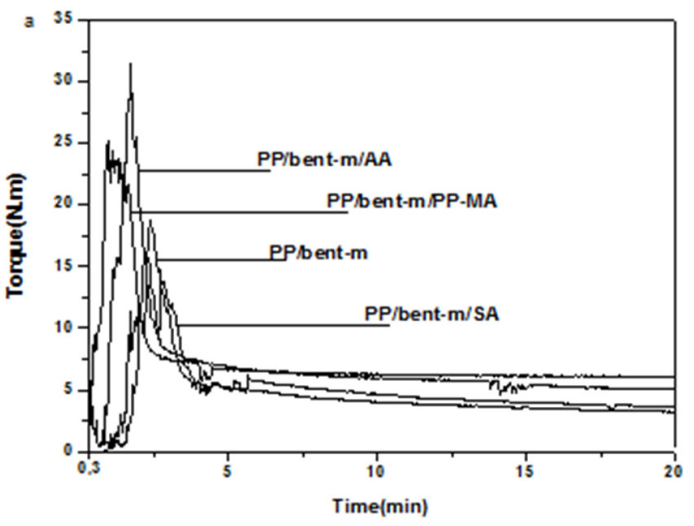

Fig. 1. Torque behavior of PP/bent-m composites

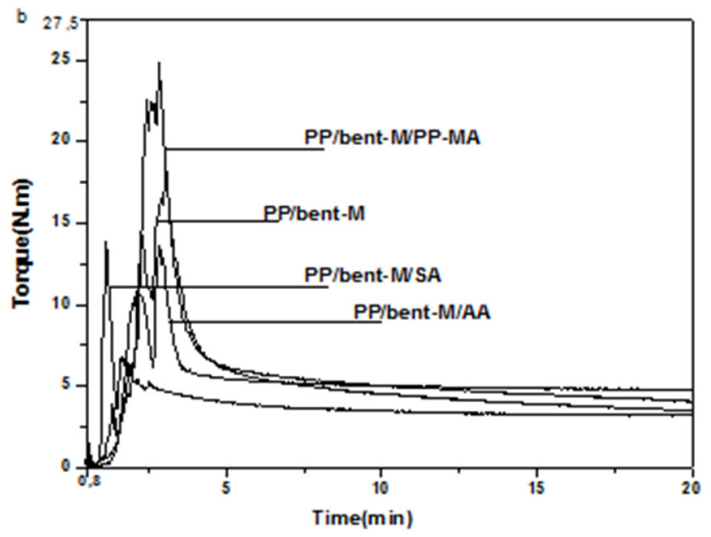

Fig. 2. Torque behavior of PP/bent-M composites

These results give possible confirmation that the stearic acid is acting as a coupling modifier and lubricant. The enhancement of lubricity through the processing provided fine dispersion of the filler, and it was also in accord with the decrease in dimension and quantity of agglomerates showed by the SEM. This was in agreement with the findings of the authors of [23], who reported that during the processing of the $\mathrm{PP} /$ modified bentonite composites, the stearic acid is acting as an interface modifier and lubricant and thus decreases the viscosity of the melt compound due to the free movement of the polymer chains. These effects enhanced the mechanical behavior by improving the elongation at break of the composite. On the other hand, bent-M showed a different behavior than the bent-m with the addition of $5 \%$ of AA coupling agent. The torque decreased to $14 \mathrm{~N} . \mathrm{m}$ in PP/bent$\mathrm{M} / \mathrm{SA}$ and to $11 \mathrm{~N} . \mathrm{m}$ in $\mathrm{PP} / \mathrm{bent}-\mathrm{M} / \mathrm{AA}$ composites. The reduction in the torque values observed in this case is important and can be attributed to a decrease in particle/particle interaction which showed that different SA and AA coupling 
agents act as external lubricants that are able to facilitate the processing of the $\mathrm{PP} /$ bent-M composites.

Authors in [35] studied the effect of palm oil fatty acid and polypropylene grafted-maleic anhydride compatibilizers on the peak torque of bentonite filled PP. They showed that the incorporation of these coupling agents decreases the torque generated during mixing and the agents serve as external lubricants. The torque values of $\mathrm{PP} / \mathrm{bent}-\mathrm{m}$ composites in the presence of AA and PP-MA are higher. This behavior can be attributed to the good adhesion between the PP matrix and bent-m in the presence of these coupling agents, which may inhibit the chain flexibility and increase the composite torque. Authors in [36] showed that the viscosity of hexamethylenediamine modified $\mathrm{PP} /$ montmorillonite nanocomposites is higher than that of the pure $\mathrm{PP}$ in the presence of maleic anhydride grafted polypropylene. Clearly, in $\mathrm{PP} /$ bent-M composites, the integration of AA reduces the quantity of the generated torque during mixing as compared to $\mathrm{PP} /$ bent-m composites. The possible reason for the differences between the behaviors of the two bentonites (bent- $m$ and bent$\mathrm{M})$ in the presence of AA is the dissimilarity in particle size distribution: bent-M presents large particles with average particle size of $24.8 \mu \mathrm{m}$ which can form agglomerates. The introduction of AA as a coupling agent reduces particle-particle interaction resulting in the decrease of particle agglomeration and an enhancement of dispersion and flow properties.

\section{B. $X R D$}

Figure 3 presents the XRD patterns of coupled PP/bent-m samples, revealing reflections assigned to planes (110), (040), (130), and (041) as reported in $[37,38]$.

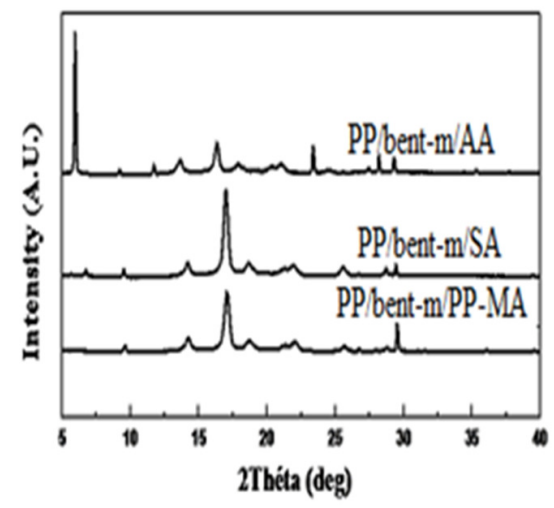

Fig. 3. XRD spectra of PP/bent-m composites.

The addition of AA in PP/bent-m/AA samples exhibited reflections with diffractions angles around $11.75^{\circ}$ and $23.4^{\circ}$. This result suggests the occurrence of partial decomposition of the organic modifier of AA during the mixing process with bentonite [39] or implies that partially intercalated structure took place in composite containing the AA coupling modifier. $\mathrm{PP} /$ bent-m/PP-MA composite was not influenced after blending and forming. The peak that appears for the diffraction angle around $6^{\circ}$ in $\mathrm{PP} /$ bent-m/SA composite is due to the amount of stearic acid introduced as a coupling modifier. These results are in good agreement with the findings of the authors in [24] who reported that the addition of stearic acid as interface modifier showed the same peak at around $6^{\circ}$ and provided better intercalation of the silicate layers in its nanocomposites when compared to the rest of the PP/bentonite nanocomposites. Similar diffraction patterns were also observed for the composites with bent-M and with different coupling agents (not shown for brevity).

\section{FTIR Spectra}

Figure 4 shows the FT-IR spectra of bentonite (bent-m and bent-M). The bands obtained at $3600-3200 \mathrm{~cm}^{-1}$ are attributed to the $\mathrm{OH}$ stretching mode of $\mathrm{Si}-\mathrm{OH}$ groups [40]. The band between $1640-1620 \mathrm{~cm}^{-1}$ belongs to the deformation of the adsorbed $\mathrm{H}_{2} \mathrm{O}$ molecules. The intense broad-band with the maximum at $1041 \mathrm{~cm}^{-1}$ ranged at $1040-1080 \mathrm{~cm}^{-1}$ corresponds to the $\mathrm{Si}-\mathrm{O}-\mathrm{Si}$ valence vibration of the $\mathrm{SiO}_{4}$. In addition, the narrow peak at $797 \mathrm{~cm}^{-1}$ corresponds to the silanol group [41] and at around $600 \mathrm{~cm}^{-1}$ corresponds to Si-O-Al [23]. The peak recorded at $1439 \mathrm{~cm}^{-1}$ is associated with the presence of calcite in the sample [42]. Bent-M shows a much larger peak than the bent- $\mathrm{m}$ as the $\mathrm{CaO}$ content is greater in the case of bent-M (7.06\% mass) than of the bent-m (3.16\% mass). On the other hand, bent-m is more hygroscopic than bent-M, because the intensity of the absorption bands at $3432.8 \mathrm{~cm}^{-1}$ and $1635 \mathrm{~cm}^{-1}$ assigned to the stretching and bending vibrations of the $\mathrm{OH}$ groups for the water molecules adsorbed on bentonite surface [43] are superior in the case of bent-m than bent-M $\left(1619 \mathrm{~cm}^{-1}\right.$, $3432.8 \mathrm{~cm}^{-1}$ ).

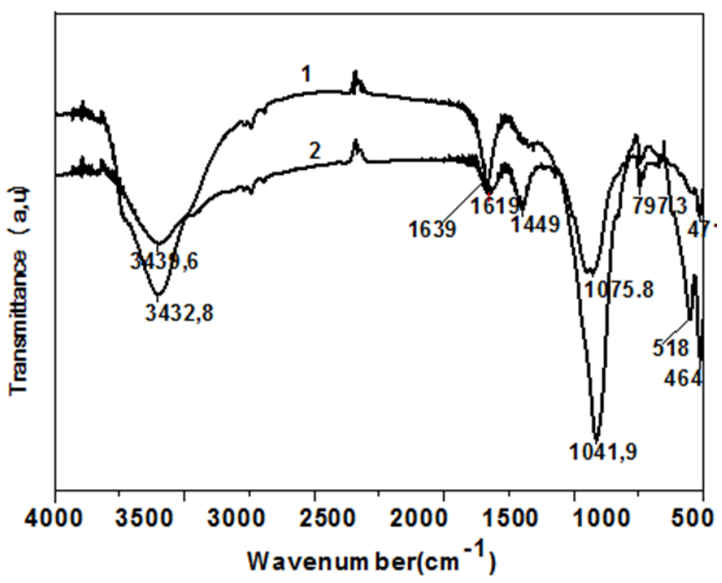

Fig. 4. FTIR spectra of (1) bent-m and (2) bent-M.

The FT-IR spectra of PP(Figure 5(a)) display absorption peaks which coincide with the literature. Methylene groups vibrations are registered in the range $1445-1485 \mathrm{~cm}^{-1}$ and methyl group vibrations are registered in the range 1430$1470 \mathrm{~cm}^{-1}$ or $1365-1395 \mathrm{~cm}^{-1}$ [44]. These peaks in our spectrum appear at 1455 and $1355 \mathrm{~cm}^{-1}$ respectively. At $2838-2982 \mathrm{~cm}^{-1}$, the peaks are attributed to the asymmetric and symmetric $\mathrm{CH}$ bands [40]. The characteristic vibrations of terminal unsaturated $\mathrm{CH}_{2}$ group absorbs at 840,1000 , and $1170 \mathrm{~cm}^{-1}$ [44]. These peaks are detected in our spectrum at 840, 980, and $1170 \mathrm{~cm}^{-1}$ (Figure 5(a)). The FT-IR spectra in Figure 5(c) and Figure 5(d) display the contribution of AA in PP/bent-m and $\mathrm{PP} /$ bent-M composites. Again the bands at $950-1080 \mathrm{~cm}^{-1}$ are 
characteristic of the asymmetric and symmetric vibrations of $\mathrm{Si}-\mathrm{O}-\mathrm{Si}$. The bands ranged generally at $1540-1640 \mathrm{~cm}^{-1}$ attest of the stretching vibrations of $\mathrm{CO}_{2}$ [45]. In our spectrum, there were registered at $1512-1608 \mathrm{~cm}^{-1}$. The bending vibrations due to the symmetric $\mathrm{CH}_{3}$ and due to $\mathrm{HCH}$ band absorb at $1385.5 \mathrm{~cm}^{-1}$ were generally detected at $1408 \mathrm{~cm}^{-1}$ [45]. This one disappeared in our composites. On the other hand, a differentiated absorption at $1295.5 \mathrm{~cm}^{-1}$ associated with the bending vibration of $\mathrm{CH}_{3}$, stretching of $\mathrm{CC}$ and rocking of $\mathrm{CH}$ also disappeared in our composites. The peak in the spectra of pure AA at $1239 \mathrm{~cm}^{-1}$ (Figure $5(\mathrm{~b})$ ) is attributed to the rocking of $\mathrm{NH}_{3}$ and bending of $\mathrm{COH}$, the intensity of the corresponding peak in our composites was decreased at this range. The peak generally located at $1133 \mathrm{~cm}^{-1}$ was attributed to the $\mathrm{CC}$ stretch [45], and was seen at $1146 \mathrm{~cm}^{-1}$. There is a displacement toward the high frequency region $1150 \mathrm{~cm}^{-1}$ in our composites (Figure $5(\mathrm{c})-(\mathrm{d}))$. While $769 \mathrm{~cm}^{-1}$ is the peak of the bending of $\mathrm{CO}_{2}$, a weak signal in the corresponding band was observed in our composites and these remarks suggested the immobilization of AA on the surface of bentonite.

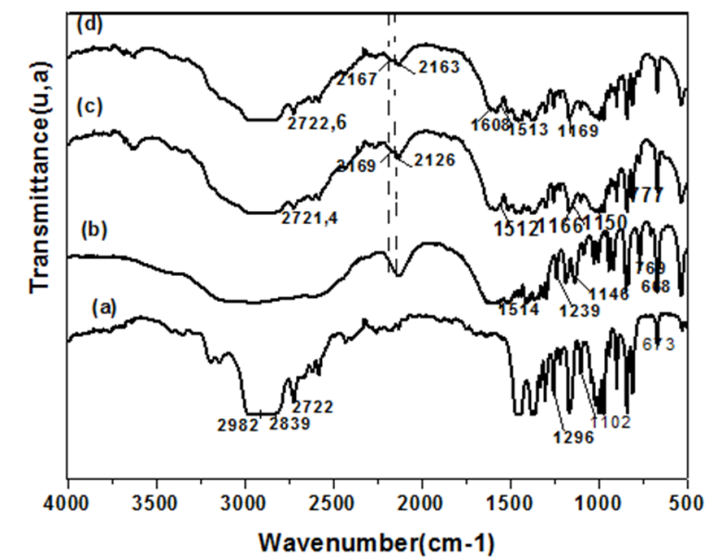

Fig. 5. FTIR spectra of (a) neat PP, (b) AA, (c) PP/bent-m/AA, and (d) $\mathrm{PP} /$ bent-M/AA

The FTIR spectra of the pure PP-MA film (Figure 6(b)) are characterized by the presence of two bands typical of the pure PP-MA at $1783 \mathrm{~cm}^{-1}$ and $1717 \mathrm{~cm}^{-1}$ which are attributed to the symmetric and asymmetric stretching vibration of the $\mathrm{C}=\mathrm{O}$ group. The FTIR spectra of the composite in Figure 6(c)-(d) shows very weak peaks at $1783 \mathrm{~cm}^{-1}$ and $1717 \mathrm{~cm}^{-1}$ which attest the small amount of the carbonyl in a polymer molecule. C-O group is registered in the range of $1190-960 \mathrm{~cm}^{-1}$ in pure PPMA [44]. In our case, C-O absorption was detected at 1165 $\mathrm{cm}^{-1}$. It was observed that this absorption intensity is less strong in $\mathrm{PP} / \mathrm{bent}-\mathrm{m} / \mathrm{PP}-\mathrm{MA}$ composite and diminished in $\mathrm{PP} / \mathrm{bent}-$ M/PP-MA composite. Also, the peak characteristic of C-O group shifted to $1167 \mathrm{~cm}^{-1}$ in $\mathrm{PP} / \mathrm{bent}-\mathrm{m} / \mathrm{PP}-\mathrm{MA}$. This suggested the presence of new hydrogen bands between PPMA and bent-m. In the case of neat SA (Figure 7(b)), broad and intense bands observed at $2916 \mathrm{~cm}^{-1}$ and $2858 \mathrm{~cm}^{-1}$ are attributed to the stretching vibration of $\mathrm{C}-\mathrm{H}$ bands located generally in range of $2800-2900 \mathrm{~cm}^{-1}$. The absorption in this region showed very weak peaks in the spectrum of composite (Figure 7(c)-(d)). Also, the original $\mathrm{C}=\mathrm{O}$ absorption at 1704 $\mathrm{cm}^{-1}$ of SA shifted by $4 \mathrm{~cm}^{-1}$ toward the high frequency region in the composites with SA. Apparently these changes are due to the adsorption of SA on bentonite as reported in [24].

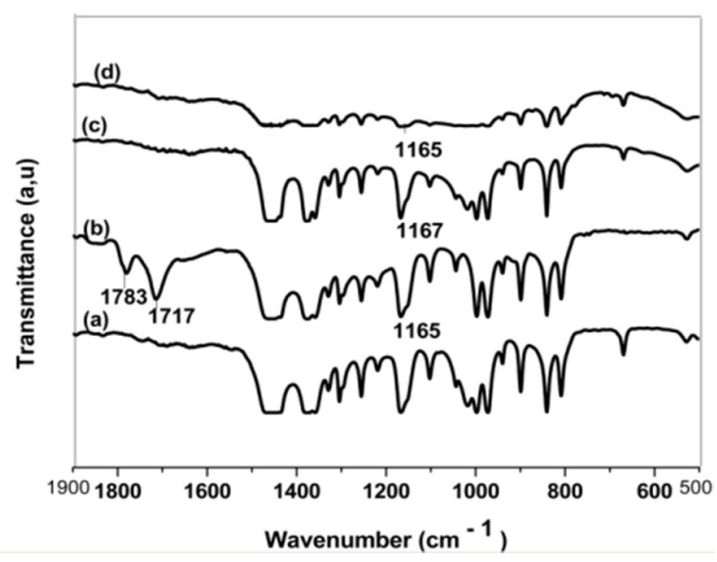

Fig. 6. FTIR spectra of (a) neat PP, (b) PP-MA, (c) PP/bent-m/PP-MA, and (d) PP/bent-M/PP-MA (d).

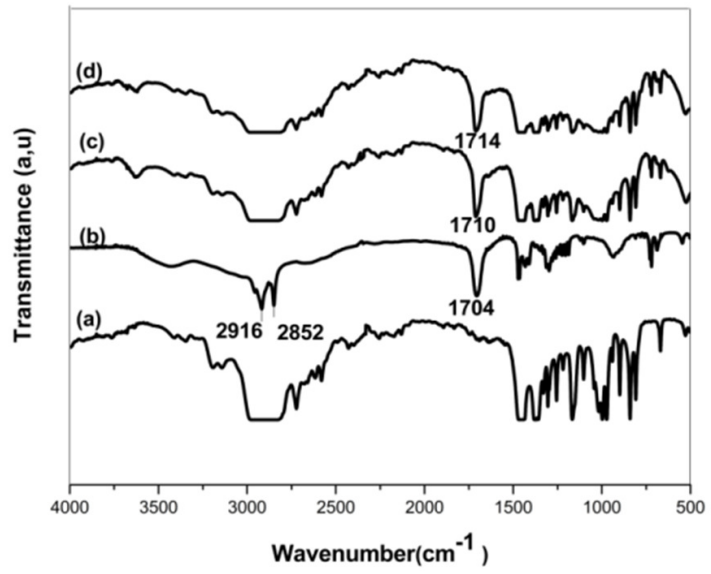

Fig. 7. FTIR spectra of (a) neat PP, (b) SA, (c) PP/bent-m/SA, and (d) $\mathrm{PP} /$ bent-M/SA.

\section{Scanning Electron Microscopy of Film Surface}

The morphologies of the film surface of uncoupled and coupled PP/bent-m and PP/bent-M composites are presented in Figures 8 and 9 respectively. SEM micrographs show microsized particles of $5 \mathrm{wt} \%$ clay in PP/bent-m composite (Figure $10)$, which is larger as compared to particles in coupled composites. This indicates an inhomogeneous distribution of clay in PP in the absence of a coupling agent. With further inclusion of SA and AA coupling agents, the presence of agglomerates in bent-m is almost unnoticeable, which is attributed to the good dispersion of bentonite bent-m in the PP matrix in the presence of these coupling modifiers and clarified the enhancement in some mechanical properties. Stearic acid as coupling agent introduces an improved wetting of bentonite particles through the matrix of PP, owing to interactions between clay and PP. In this case, bentonite layers were aggregated with a size of $195 \mathrm{~nm}$ in the polypropylene matrix. 


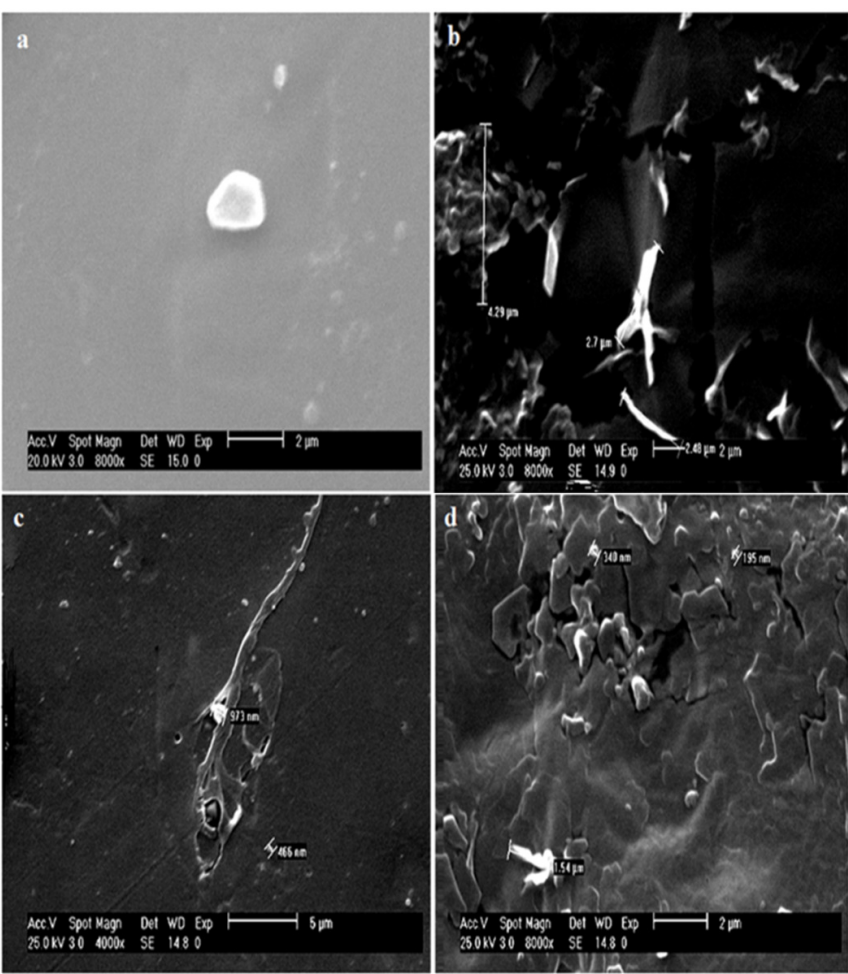

Fig. 8. SEM micrographs of (a) PP/bent-m, (b) PP/bent-m/PP-MA, (c) $\mathrm{PP} /$ bent-m/AA, and (d) PP/bent-m/SA.

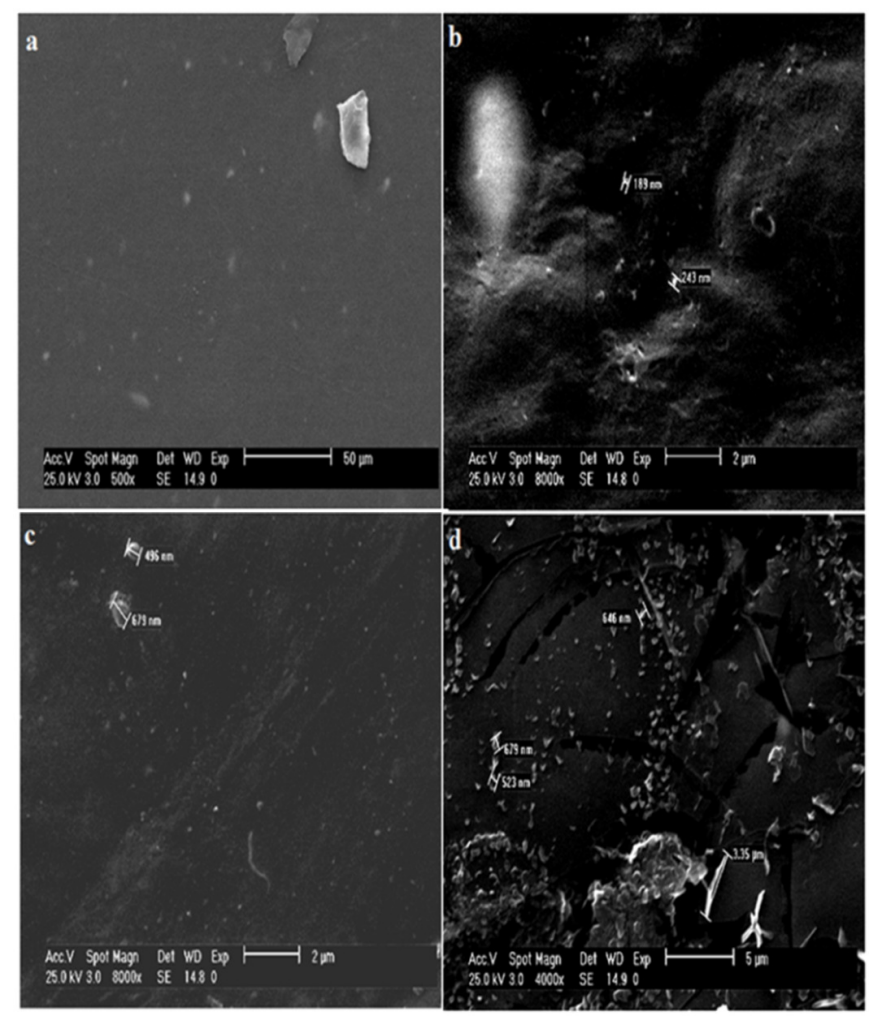

Fig. 9. SEM micrographs of (a) PP/bent-M, (b) PP/bent-M/PP-MA, (c) $\mathrm{PP} /$ bent-M/AA, and (d) PP/bent-M/SA.
The SEM micrographs of PP/bent-M composites (Figure 9) with a clay content of $5 \mathrm{wt} \%$ showed that the uncoupled composite included a small quantity of agglomerates of clay of size less than $50 \mu \mathrm{m}$. By adding AA and SA coupling agents in the composite, no detectable particle agglomerates were observed at $2 \mu \mathrm{m}$ scale. This behavior indicates a good dispersion of bent-M in PP matrix in the presence of amino acid and stearic acid coupling agents. However, the PP/bentM/PP-MA micrograph shows large aggregates. The structure (Figure 9(b)) observed in PP/bent-m/SA can be attributed to the needles structure of stearic acid and to the good dispersion of bent- $\mathrm{m}$ in the PP matrix in the presence of this coupling agent.

\section{E. Differential Scanning Calorimeter Properties}

Table I illustrates the values of the crystallinity content $\left(X_{c}\right)$ calculated from $\Delta H_{m}$ which is the enthalpy of melting of polymer in the composite, compared with the enthalpy of melting of $100 \%$ crystalline $\mathrm{PP}$, the melting temperature $\left(T_{m}\right)$ and the crystallization temperature $\left(T_{c}\right)$ of all prepared samples. Each composite in the presence of coupling agent exhibits similar $T_{m}$ regardless of the kind of bentonite. It is noticeable that $T_{m}$ and $T_{c}$ remained unaffected with the incorporation of the clay in the presence of different coupling agents in all composites, indicating that the crystal size of PP did not change [46]. The degree of crystallinity increased slightly in PP-MA and SA coupled composites as compared to that in pure PP $(51 \%)$ and in uncoupled composite. PP/bent-m/PP-MA and $\mathrm{PP} /$ bent-M/SA present the higher degree of crystallinity, around $57 \%$, while $\mathrm{PP} /$ bent-M/AA provides the lowest crystallinity due to the lower enthalpy of melting of the compatibilizer. This result confirms how the crystallization of PP matrix varied with the further inclusion of PP-MA, AA, and SA coupling agents [39]. The percentage of crystallinity did not change with the addition of bentonite. This signifies that the bentonite did not act as a nucleating agent in this compound. According to [36], the presence of coupling agents appears to decrease the crystallization process in bentonite filled PP composite and bentonite did not serve as nucleating agent in this system.

TABLE I. CHARACTERISTIC THERMAL PARAMETERS OF PP/BENT COMPOSITES WITH AND WITHOUT COUPLING AGENTS

\begin{tabular}{|c|c|c|c|c|c|}
\hline Samples & $\begin{array}{c}\boldsymbol{T}_{\boldsymbol{m}} \\
\left({ }^{\circ} \mathbf{C}\right)\end{array}$ & $\begin{array}{c}\Delta \boldsymbol{H}_{\boldsymbol{m}} \\
(\mathbf{J} / \mathbf{g})\end{array}$ & $\begin{array}{c}\boldsymbol{T}_{\boldsymbol{c}} \\
\left({ }^{\circ} \mathbf{C}\right)\end{array}$ & $\begin{array}{c}\Delta \boldsymbol{H}_{\boldsymbol{c}} \\
(\mathbf{J} / \mathbf{g})\end{array}$ & $\begin{array}{c}\boldsymbol{X} \\
\boldsymbol{\%}\end{array}$ \\
\hline Neat PP & 165 & 107 & 126 & 113 & 51 \\
\hline PP/bent-m & 166 & 103 & 127 & 110 & 52 \\
\hline PP-bent-M & 166 & 102 & 127 & 109 & 52 \\
\hline $\mathbf{P P / b e n t - m / P P - M A}$ & 165 & 106 & 127 & 109 & 57 \\
\hline $\mathbf{P P / b e n t - m / S A}$ & 164 & 101 & 127 & 104 & 54 \\
\hline PP/bent-m/AA & 165 & 99 & 127 & 108 & 53 \\
\hline PP/bent-M/PP-MA & 165 & 103 & 126 & 109 & 55 \\
\hline PP/bent-M/SA & 164 & 107 & 127 & 107 & 57 \\
\hline PP/bent-M/AA & 165 & 93 & 127 & 103 & 50 \\
\hline
\end{tabular}

\section{F. Mechanical Properties}

The results of mechanical properties of PP and uncoupled and coupled PP/bent composites are exhibited in Table II. We observe a decrease in Young's modulus caused by the bent-M filler which appears to be related to the amount of clay and the size filler. The Young's modulus of PP/bent-M/AA composite 
was still improved even when compared to the other composites of PP/bent-M coupled to PP-MA or SA. The changes in Young's modulus reflect the nature of the interface between polymer and filler. The introduction of bent- $m$ in PP provides a slight decrease in Young's modulus and PP/bent$\mathrm{m} / \mathrm{SA}$ had the same stiffness as the uncoupled composite. No changes of Young's modulus in PP/bent-m coupled to PP-MA were observed, while this property was more improved for $\mathrm{PP} /$ bent-m/AA composite due to the effective adhesion between PP and clay in the presence of AA coupling agent, conducted by the homogeneous dispersion as shown by the SEM images, providing an easy transfer of load throughout the composite [47]. As expected at $5 \mathrm{wt} . \%$ of clay content, there is a significant decrease in elongation at break. The elongation at break for neat PP is above $140 \%$ and decreases to $103 \%$ especially in PP/bent-m. This decrease could be caused by the fact that the inorganic particles of filler are rigid and cannot be deformed by external stress in the samples but acted only as stress concentrators during the deformation process [36]. A significant decrease in elongation at break was reported in [48] for LDPE/TPS/SNC nanocomposites by adding $5 \mathrm{wt} \%$ of starch nanocrystals (SNC) without DCP compared to pure LDPE. By introducing PP-MA coupling agent, an enhancement in elongation at break of about $21 \%$ is observed compared to uncoupled PP/bent-m composite. However, the percentage of improvement in elongation at break by using SA in PP/bent-m compound is $37 \%$. This increase in ductility (i.e. elongation at break) might be due to the existence of fatty acids in SA which act as interface modifiers for bentonite into the PP matrix. Consequently, the ductility of bentonite filled PP composites can be improved [35]. These results prove the results of torque values. According to $[24,35]$, fatty acids promote an improvement in elongation at break and the dispersion state of nanoclay and bentonite in a polypropylene matrix. It has been noted [35] that the elongation at break of composites under the presence of Palm Oil Fatty Acid (POFA) additive shows the highest value compared to composites with the presence of PPMA. A similar trend is observed for the elongation at break and the strain at break change for all samples. Table II shows a reduction of the maximum stress by the incorporation of the unmodified bent- $\mathrm{m}$ or bent-M filler. This behavior can be explained by the low adhesion between bentonite and the PP matrix. The unmodified bentonite particles in uncoupled composite can serve as sites to initiate and activate the deformation mechanism and as a result, the yield stress decreases. On the other hand, there are some bentonite layers with good matrix adhesion based on SEM micrographs in $\mathrm{PP} /$ bent-m and PP/bent-M composites coupled with PP-MA coupling agent. These ones can withstand the movement of the polymer chains and therefore increase the yield stress. Improvement in yield values by the introduction of PP-MA compatibilizer in PP/modified clay has been reported in [49]. For coupled composites in the presence of SA and AA coupling agents and because they act as external lubricants in $\mathrm{PP} /$ bent-M composites (as seen on the torque results), free movement of the polymer chains is possible. The latter makes the physical sliding between the molecular segments easier which results in the decrease of the maximum stress. The same remark was noted for the coupled $\mathrm{PP} / \mathrm{bent}-\mathrm{m} / \mathrm{SA}$ composite. From the results of this study, it can be supposed that the AA and SA coupling modifiers show certain degrees of interactions in the PP/bentonite system as observed in some improvement on mechanical properties. These interactions are superior for bent-m because of its low average particle size compared to bent-M.

TABLE II. VALUES OF STIFFNESS, ELONGATION AT BREAK, STRAIN BREAK, AND MAXIMUM STRESS OF PP/BENTONITE

\begin{tabular}{|c|c|c|c|c|}
\hline Samples & $\begin{array}{c}\text { Young's } \\
\text { Modulus } \\
\text { (MPa) }\end{array}$ & $\begin{array}{c}\text { Elongation } \\
\text { at break \% }\end{array}$ & $\begin{array}{c}\text { Strain } \\
\text { break } \\
\text { \% }\end{array}$ & $\begin{array}{c}\text { Maximum } \\
\text { stress } \\
\text { (MPa) }\end{array}$ \\
\hline Neat PP & $1538 \pm 20$ & $145 \pm 4$ & $7.3 \pm 0.2$ & $37.9 \pm 0.2$ \\
\hline PP/bent-m & $1516 \pm 6$ & $103 \pm 3$ & 5.30 .4 & $34.0 \pm 0.6$ \\
\hline PP-bent-M & $1467 \pm 7$ & $136 \pm 8$ & $6.8 \pm 0.4$ & $35.5 \pm 0.1$ \\
\hline $\begin{array}{c}\text { PP/bent-m/PP- } \\
\text { MA }\end{array}$ & $1539 \pm 5$ & $125 \pm 3$ & $6.3 \pm 0.2$ & $35.8 \pm 0.3$ \\
\hline PP/bent-m/SA & $1516 \pm 24$ & $141 \pm 1$ & $7 \pm 1$ & $32.5 \pm 0.2$ \\
\hline PP/bent-m/AA & $1719 \pm 52$ & $83 \pm 4$ & $4.2 \pm 0.2$ & $30.5 \pm 0.4$ \\
\hline $\mathbf{P P / b e n t - M / P P - M A}$ & $1435 \pm 23$ & $123 \pm 0.1$ & $6.1 \pm 0.3$ & $37.0 \pm 0.4$ \\
\hline $\mathbf{P P / b e n t - M / S A}$ & $1481 \pm 31$ & $79 \pm 2$ & $3.9 \pm 0.5$ & $31.5 \pm 0.8$ \\
\hline $\mathbf{P P / b e n t - M / A A}$ & $1532 \pm 13$ & $94 \pm 0.1$ & $4.7 \pm 0.5$ & $29.6 \pm 0.2$ \\
\hline
\end{tabular}

\section{G. Thermogravimetric Analysis (TGA)}

TGA was employed to evaluate the thermal stability of each sample. Figure 10 shows the TGA curves of neat PP, PP/bent$\mathrm{m}$, and $\mathrm{PP} /$ bent-M composites in the presence of different coupling agents. We do not observe an improvement in $T_{5 \%}$ in all cases of coupled $\mathrm{PP} /$ bentonite systems (excepted $\mathrm{PP} / \mathrm{bent}-$ m/AA). The temperature at $20 \%$ weight loss of all composites enhanced (excepted PP/bent-M/SA). The coupling agent can improve the stability at high temperatures [50]. The temperature at $50 \%$ weight loss of $\mathrm{PP} / \mathrm{bent}-\mathrm{m} / \mathrm{SA}$ displays the highest value. This composite is more stable than neat PP, while a slight decrease is shown in PP/bent-M/SA. Adding AA to $\mathrm{PP} /$ bent-m and $\mathrm{PP} /$ bent-M results in a lower improvement of $T_{50 \%}$ compared to SA (there is about $13^{\circ} \mathrm{C}$ of $T_{50 \%}$ improvement as compared to neat PP). PP-MA displays a slight increase in $T_{50 \%}$ in both $\mathrm{PP} /$ bent-m and $\mathrm{PP} /$ bent-M. However, there is an improvement in overall coupled composites in $T_{\max }$, the highest being recorded for $\mathrm{PP} / \mathrm{bent}-\mathrm{m} / \mathrm{SA}$ composite. It is noted that these materials become more thermally stable due to an improvement in the miscibility between all the added coupling agents [51]. Also, thermal stability enhancement is a consequence of the fine dispersion of bentonite within the PP matrix and the interface which resulted in slower escape of decomposed smaller molecules[39, 52-53].

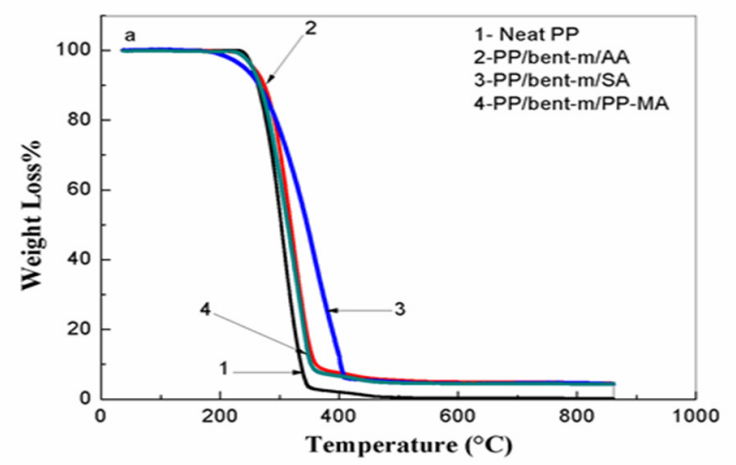

Fig. 10. TGA curves of selected samples of PP with PP/bent-m composites 


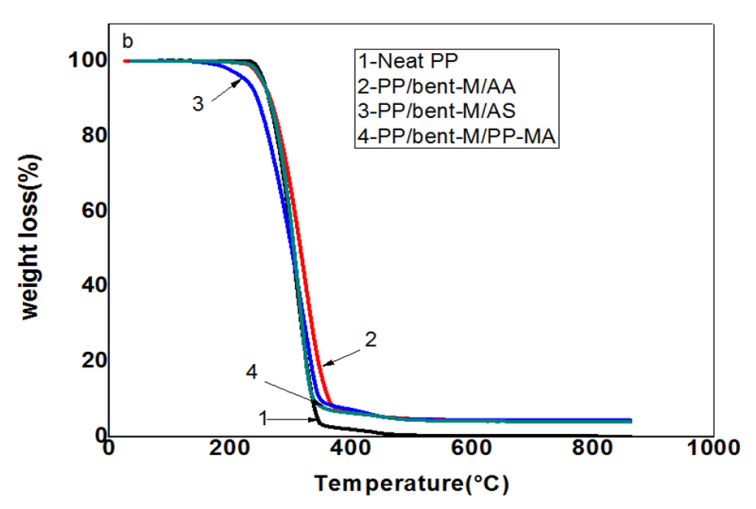

Fig. 11. TGA curves of selected samples of PP with PP/bent-M composites

TABLE III. THERMOGRAVIMETRIC PARAMETERS OF PP AND PP/BENTONITE COPOSITES IN THE AIR

\begin{tabular}{|c|c|c|c|c|}
\hline Samples & $\begin{array}{c}\boldsymbol{T}_{\mathbf{5} \%} \\
\left({ }^{\circ} \mathbf{C}\right)\end{array}$ & $\begin{array}{c}\boldsymbol{T}_{\mathbf{2 0} \%} \\
\left({ }^{\circ} \mathbf{C}\right)\end{array}$ & $\begin{array}{c}\boldsymbol{T}_{\mathbf{5 0} \%} \\
\left({ }^{\circ} \mathbf{C}\right)\end{array}$ & $\begin{array}{c}\boldsymbol{T}_{\boldsymbol{m a x}} \\
\left({ }^{\circ} \mathbf{C}\right)\end{array}$ \\
\hline Neat PP & 254 & 278 & 303 & 306 \\
\hline PP/bent-m/PP-MA & 252 & 279 & 305 & 336 \\
\hline PP/bent-m/SA & 241 & 294 & 347 & 353 \\
\hline PP/bent-m/AA & 256 & 291 & 319 & 324 \\
\hline PP/bent-M/PP-MA & 251 & 280 & 305 & 316 \\
\hline
\end{tabular}

This increase in the decomposition temperature of about $40^{\circ} \mathrm{C}$, as compared with the neat polymer, might be taken as a sign of the incidence of clay intercalation, since the intercalated or exfoliated clay will act as a barrier to the diffusion of atmospheric oxygen in the compound, inhibiting the polymer decomposition [54]. Recently, it was reported that the incorporation of fatty acids like stearic acid between the layers of mineral ceramic facilitates polymer-ceramic interaction [55]. The degradation temperatures of all samples are listed in Table III.

\section{CONCLUSIONS}

This study has investigated the effect of the addition of different coupling agents such as PP-MA, SA, and AA on the mechanical properties, thermal stability, crystallinity, and rheological properties of PP/raw bentonite composites. Fillers such as bentonite without treatment can be used as good reinforcement. According to XRD results, polar molecules of AA exhibited reflections that shift to smaller angles. This is an indication that AA was introduced in bentonite. PP/bent-m/PP$\mathrm{MA}$ and PP/bent-M/SA composites present the higher degree of crystallinity of around $57 \%$ as compared to neat PP and uncoupled composites. $\mathrm{PP} / \mathrm{bent}-\mathrm{m} / \mathrm{SA}$ composite is more stable than neat matrix while the improvement in decomposition temperature is about $13^{\circ} \mathrm{C}$ in $\mathrm{PP} /$ bent-m/AA composite. The presence of the different coupling agents in natural bentonite increases $T_{\max }$ in all the composites. The PP/bent-m/SA system can be considered as an important material, which improves the thermal stability and kept the modulus and elongation at break at a value almost similar to that of PP. In addition, PP/bentm/AA composite can also be selected as a material with high Young modulus and good thermal stability. These enhancements were important as this behavior has not been reported in the literature. In most cases the elongation at break properties are reduced in PP filled with nanoclay. Also, the increase in thermal stability and modulus of elasticity were observed after the addition of nanobentonite in the presence of stearic acid as interface modifier and not for PP/raw microbentonite composite containing $5 \mathrm{wt} . \%$ of filler and $5 \mathrm{wt} . \%$ of stearic acid or amino acid as coupling agents. The behavior of processing composites showed a decrease in torque values above the uncoupled system by using SA and AA coupling agents in $\mathrm{PP} /$ bent-M composites. The decrease is more significant in presence of SA in PP/bent-m composites.

\section{ACKNOWLEDGMENT}

The authors appreciate the financial support from the Setif 1 University.

\section{REFERENCES}

[1] T. G. Mofokeng, S. S. Ray, V. Ojijo, and R. Salehiyan, "Tuning the nano/micro-structure and properties of melt-processed ternary composites of polypropylene/ethylene vinyl acetate blend and nanoclay: The influence of kinetic and thermodynamic parameters," Journal of Applied Polymer Science, vol. 135, no. 1, 2018, Art. no. 45585, https://doi.org/10.1002/app.45585.

[2] N. Zaman, S. Ahmed, M. Sanaullah, A. U. Rehman, A. R. Shar, and M. R. Luhur, "Fabrication and Characterization of Organoclay Reinforced Polyester Based Hybrid Nanocomposite Materials," Engineering, Technology \& Applied Science Research, vol. 8, no. 3, pp. 3038-3040, Jun. 2018, https://doi.org/10.48084/etasr. 1977.

[3] B. A. A. Majeed and D. A. Sabar, "Preparations of Organoclay Using Cationic Surfactant and Characterization of PVC/ (Bentonite and Organoclay) Composite Prepared via Melt Blending Method," Iraqi Journal of Chemical and Petroleum Engineering, vol. 18, no. 1, pp. 1736, Mar. 2017.

[4] R. S. Cardoso, V. O. Aguiar, and M. de F. V. Marques, "Masterbatches of polypropylene/clay obtained by in situ polymerization and meltblended with commercial polypropylene," Journal of Composite Materials, vol. 51, no. 25, pp. 3547-3556, Oct. 2017, https://doi.org/ $10.1177 / 0021998317690444$.

[5] Y. Hernandez et al., "Improvement of toughness properties of polypropylene filled with nanobentonite using stearic acid as interface modifier," Journal of Composite Materials, vol. 51, no. 3, pp. 373-380, Feb. 2017, https://doi.org/10.1177/0021998316644852.

[6] D. D. J. Rousseaux, M. Sclavons, P. Godard, and J. Marchand-Brynaert, "Tuning the functionalization chemistry of polypropylene for polypropylene/clay nanocomposites," Reactive and Functional Polymers, vol. 72, no. 1, pp. 17-24, Jan. 2012, https://doi.org/10.1016/ j.reactfunctpolym.2011.10.005.

[7] S. K. Sharma and S. K. Nayak, "Surface modified clay/polypropylene (PP) nanocomposites: Effect on physico-mechanical, thermal and morphological properties," Polymer Degradation and Stability, vol. 94, no. 1 , pp. 132-138, Jan. 2009, https://doi.org/10.1016/j. polymdegradstab.2008.09.004.

[8] M. Alexandre and P. Dubois, "Polymer-layered silicate nanocomposites: preparation, properties and uses of a new class of materials," Materials Science and Engineering: R: Reports, vol. 28, no. 1, pp. 1-63, Jun. 2000, https://doi.org/10.1016/S0927-796X(00)00012-7.

[9] B. Uzbas and A. C. Aydin, "Microstructural Analysis of Silica Fume Concrete with Scanning Electron Microscopy and X-Ray Diffraction," Engineering, Technology \& Applied Science Research, vol. 10, no. 3, pp. 5845-5850, Jun. 2020, https://doi.org/10.48084/etasr.3288.

[10] G. Bulut, M. Chimeddorj, F. Esenli, and M. S. Çelik, "Production of desiccants from Turkish bentonites," Applied Clay Science, vol. 46, no. 2, pp. 141-147, Oct. 2009, https://doi.org/10.1016/j.clay.2009.07.013.

[11] S. Cara, G. Carcangiu, G. Padalino, M. Palomba, and M. Tamanini, "The bentonites in pelotherapy: chemical, mineralogical and technological properties of materials from Sardinia deposits (Italy)," Applied Clay Science, vol. 16, no. 1, pp. 117-124, Jan. 2000, https://doi.org/10.1016/S0169-1317(99)00049-6. 
[12] E. M. Araújo et al., "The influence of organo-bentonite clay on the processing and mechanical properties of nylon 6 and polystyrene composites," Materials Science and Engineering: B, vol. 112, no. 2, pp. 175-178, Sep. 2004, https://doi.org/10.1016/j.mseb.2004.05.027.

[13] B. Abu-Jdayil, K. Al-Malah, and R. Sawalha, "Study on BentoniteUnsaturated Polyester Composite Materials," Journal of Reinforced Plastics and Composites, vol. 21, no. 17, pp. 1597-1607, Nov. 2002, https://doi.org/10.1177/0731684402021017493.

[14] B. Abu-Jdayil and K. Al-Malah, "Jordanian Clay-Based Heat Insulator Composites: Mechanical Properties," Journal of Reinforced Plastics and Composites, vol. 27, no. 14, pp. 1559-1568, Sep. 2008, https://doi.org/ $10.1177 / 0731684407087371$

[15] N. Hasegawa, M. Kawasumi, M. Kato, A. Usuki, and A. Okada, "Preparation and mechanical properties of polypropylene-clay hybrids using a maleic anhydride-modified polypropylene oligomer," Journal of Applied Polymer Science, vol. 67, no. 1, pp. 87-92, 1998, https://doi.org/10.1002/(SICI)1097-4628(19980103)67:1<87::AIDAPP10>3.0.CO;2-2.

[16] R. Doufnoune, F. Riahi, S. Bouchareb, and A. Ourari, "Silanization of natural $\mathrm{Na}+$-maghnite algerian clay pre-intercalated with a cationic alkylphosphonium salt," Journal of Adhesion Science and Technology, vol. 33, no. 6, pp. 616-634, Mar. 2019, https://doi.org/10.1080/ 01694243.2018.1551752.

[17] W. Mo, Q. He, X. Su, S. Ma, J. Feng, and Z. He, "Preparation and characterization of a granular bentonite composite adsorbent and its application for Pb2+ adsorption," Applied Clay Science, vol. 159, pp. 68-73, Jun. 2018, https://doi.org/10.1016/j.clay.2017.12.001.

[18] D. García-López, O. Picazo, J. C. Merino, and J. M. Pastor, "Polypropylene-clay nanocomposites: effect of compatibilizing agents on clay dispersion," European Polymer Journal, vol. 39, no. 5, pp. 945950, May 2003, https://doi.org/10.1016/S0014-3057(02)00333-6.

[19] H. Baniasadi, A. Ramazani S.A., and S. Javan Nikkhah, "Investigation of in situ prepared polypropylene/clay nanocomposites properties and comparing to melt blending method," Materials \& Design, vol. 31, no. 1 , pp. 76-84, Jan. 2010, https://doi.org/10.1016/j.matdes.2009.07.014.

[20] H. Md. Akil, M. F. A. Rasyid, and J. Sharif, "Effect of Compatibilizer on Properties of Polypropylene Layered Silicate Nanocomposite," Procedia Chemistry, vol. 4, pp. 65-72, Jan. 2012, https://doi.org/ 10.1016/j.proche.2012.06.010.

[21] G. Lagaly and T. J. Pinnavia, "Clay mineral - Polymer nanocomposites," Applied Clay Science, vol. 15, no. 1-2, 1999.

[22] L. Minkova, Y. Peneva, E. Tashev, S. Filippi, M. Pracella, and P. Magagnini, "Thermal properties and microhardness of HDPE/clay nanocomposites compatibilized by different functionalized polyethylenes," Polymer Testing, vol. 28, no. 5, pp. 528-533, Aug. 2009, https://doi.org/10.1016/j.polymertesting.2009.04.001.

[23] C. D. Angel et al., "Mechanical and rheological properties of polypropylene/bentonite composites with stearic acid as an interface modifier," Journal of Applied Polymer Science, vol. 132, no. 30, 2015, https://doi.org/10.1002/app.42264.

[24] L. Gonzalez et al., "Mechanical and Thermal Properties of Polypropylene/Montmorillonite Nanocomposites Using Stearic Acid as Both an Interface and a Clay Surface Modifier," Polymer Composites, vol. 35, no. 1, Jan. 2014, https://doi.org/10.1002/pc.22627.

[25] Q. Han, R. Yang, J. Li, Y. Zhang, and C. Wang, "Synthesis of leucine micro/nanocrystals for pharmaceutical applications," CrystEngComm, vol. 13, no. 20, pp. 6157-6162, Sep. 2011, https://doi.org/10.1039/ C1CE05519D.

[26] E. G. Pradas, M. V. Sánchez, F. C. Cruz, M. S. Viciana, and M. F. Pérez, "Adsorption of cadmium and zinc from aqueous solution on natural and activated bentonite," Journal of Chemical Technology \& Biotechnology, vol. 59, no. 3, pp. 289-295, 1994, https://doi.org/10.1002/jctb. 280590312.

[27] H. Khalaf, O. Bouras, and V. Perrichon, "Synthesis and characterization of Al-pillared and cationic surfactant modified Al-pillared Algerian bentonite," Microporous Materials, vol. 8, no. 3, pp. 141-150, Feb. 1997, https://doi.org/10.1016/S0927-6513(96)00079-X.
[28] O. Bouras, J.-C. Bollinger, M. Baudu, and H. Khalaf, "Adsorption of diuron and its degradation products from aqueous solution by surfactantmodified pillared clays," Applied Clay Science, vol. 37, no. 3, pp. 240250, Sep. 2007, https://doi.org/10.1016/j.clay.2007.01.009.

[29] Y. Tang et al., "Preparation and thermal stability of polypropylene/montmorillonite nanocomposites," Polymer Degradation and Stability, vol. 82, no. 1, pp. 127-131, Jan. 2003, https://doi.org/ 10.1016/S0141-3910(03)00173-3.

[30] K.-N. Kim, H. Kimm, and J.-W. Lee, "Effect of interlayer structure, matrix viscosity and composition of a functionaiized polymer on the phase structure of polypropylene-montmorillonite nanocomposites," Polymer Engineering \& Science, vol. 41, no. 11, pp. 1963-1969, 2001, https://doi.org/10.1002/pen.10892.

[31] D. Marchant and K. Jayaraman, "Strategies for Optimizing Polypropylene-Clay Nanocomposite Structure," Industrial \& Engineering Chemistry Research, vol. 41, no. 25, pp. 6402-6408, Dec. 2002, https://doi.org/10.1021/ie011022c.

[32] W. Lertwimolnun and B. Vergnes, "Influence of compatibilizer and processing conditions on the dispersion of nanoclay in a polypropylene matrix," Polymer, vol. 46, no. 10, pp. 3462-3471, Apr. 2005, https://doi.org/10.1016/j.polymer.2005.02.018.

[33] M. J. Solomon, A. S. Almusallam, K. F. Seefeldt, A. Somwangthanaroj, and P. Varadan, "Rheology of Polypropylene/Clay Hybrid Materials," Macromolecules, vol. 34, no. 6, pp. 1864-1872, Mar. 2001, https://doi.org/10.1021/ma001122e.

[34] B. Wunderlich, "Athas table of thermal properties of linear macromolecules," in Thermal Analysis, London, UK: Academic Press Limited, 1990, pp. 417-431.

[35] N. Othman, H. Ismail, and M. Mariatti, "Effect of compatibilisers on mechanical and thermal properties of bentonite filled polypropylene composites," Polymer Degradation and Stability, vol. 91, no. 8, pp. 1761-1774, Aug. 2006, https://doi.org/10.1016/j.polymdegradstab. 2005.11.022.

[36] S. Sánchez-Valdes et al., "Effect of different amine modified clays on the compatibility and clay dispersion of polypropylene nanocomposites," e-Polymers, vol. 9, no. 1, Dec. 2009, https://doi.org/10.1515/ epoly.2009.9.1.1499.

[37] B. Kim, S.-H. Lee, D. Lee, B. Ha, J. Park, and K. Char, "Crystallization Kinetics of Maleated Polypropylene/Clay Hybrids," Industrial \& Engineering Chemistry Research, vol. 43, no. 19, pp. 6082-6089, Sep. 2004, https://doi.org/10.1021/ie049825y.

[38] P. Liborio, V. A. Oliveira, and M. de F. V. Marques, "New chemical treatment of bentonite for the preparation of polypropylene nanocomposites by melt intercalation," Applied Clay Science, vol. 111, pp. 44-49, Jul. 2015, https://doi.org/10.1016/j.clay.2015.04.003.

[39] F.-C. Chiu, H.-Z. Yen, and C.-E. Lee, "Characterization of PP/HDPE blend-based nanocomposites using different maleated polyolefins as compatibilizers," Polymer Testing, vol. 29, no. 3, pp. 397-406, May 2010, https://doi.org/10.1016/j.polymertesting.2010.01.004.

[40] E. M. Essassi, M. Yahya, S. El Kazzouli, and M. Bousmina, "Synthesis and characterization of new organophilic clay. Preparation of polystyrene/clay nanocomposite," Scientific Study \& Research: Chemistry \& Chemical Engineering, Biotechnology, Food Industry, vol. 19, no. 2, pp. 193-202, Jul. 2018.

[41] S. Yu. Khashirova, Yu. I. Musaev, A. K. Mikitaev, Yu. A. Malkanduev, and M. Kh. Ligidov, "Hybrid nanocomposites based on guanidine methacrylate monomer and polymer and layered aluminosilicates: Synthesis, structure, and properties," Polymer Science Series B, vol. 51, no. 9, Nov. 2009, Art. no. 377, https://doi.org/10.1134/ S1560090409090085.

[42] H. Olphen and J. J. Fripiat, Data handbook for clay materials and other non-metallic minerals. Oxford, UK: Pergamon Press, 1979.

[43] M. El Bouraie and A. A. Masoud, "Adsorption of phosphate ions from aqueous solution by modified bentonite with magnesium hydroxide $\mathrm{Mg}(\mathrm{OH}) 2$," Applied Clay Science, vol. 140, pp. 157-164, May 2017, https://doi.org/10.1016/j.clay.2017.01.021.

[44] S. Kumar, "Spectroscopic studies of valine and leucine molecules a comparative study," vol. 2011, no. 39, pp. 4996-4999, 2011. 
[45] B. H. Stuart, Polymer Analysis, 1st ed. Chichester, NY, USA: Wiley, 2002.

[46] V. S. Kumar, "Thermal Properties of Polypropylene/Montmorillonite Nanocomposites," Indian Journal of Science and Technology, vol. 7, no. Suppl. 7, Jan. 2015, https://doi.org/10.17485/ijst/2014/v7sp7.3.

[47] E. Kontou, M. Niaounakis, and P. Georgiopoulos, "Comparative study of PLA nanocomposites reinforced with clay and silica nanofillers and their mixtures," Journal of Applied Polymer Science, vol. 122, no. 3, pp. 1519-1529, 2011, https://doi.org/10.1002/app.34234.

[48] S. Chaoui, D. Smail, A. Hellati, and D. Benachour, "Effect of Starch Nanocrystals on the Properties of Low Density Polyethylene/Thermoplastic Starch Blends," Engineering, Technology \& Applied Science Research, vol. 10, no. 4, pp. 5875-5881, Aug. 2020, https://doi.org/10.48084/etasr.3608.

[49] B. Akbari and R. Bagheri, "Influence of PP-g-MA on morphology, mechanical properties and deformation mechanism of copolypropylene/clay nanocomposite," Journal of Applied Polymer Science, vol. 114, no. 6, pp. 3751-3759, 2009, https://doi.org/10.1002/ app.30847.

[50] J. Son, D. J. Gardner, S. O’Neill, and C. Metaxas, "Understanding the viscoelastic properties of extruded polypropylene wood plastic composites," Journal of Applied Polymer Science, vol. 89, no. 6, pp. 1638-1644, 2003, https://doi.org/10.1002/app.12372.

[51] J. M. Quiroz-Castillo et al., "Preparation and Characterization of Films Extruded of Polyethylene/Chitosan Modified with Poly(lactic acid)," Materials, vol. 8, no. 1, pp. 137-148, Jan. 2015, https://doi.org/ 10.3390/ma8010137.

[52] H. Qin et al., "Thermal stability and flammability of polypropylene/montmorillonite composites," Polymer Degradation and Stability, vol. 85, no. 2, pp. 807-813, Aug. 2004, https://doi.org/10.1016/ j.polymdegradstab.2004.03.014.

[53] J. Morawiec, A. Pawlak, M. Slouf, A. Galeski, E. Piorkowska, and N. Krasnikowa, "Preparation and properties of compatibilized LDPE/organo-modified montmorillonite nanocomposites," European Polymer Journal, vol. 41, no. 5, pp. 1115-1122, May 2005, https://doi.org/10.1016/j.eurpolymj.2004.11.011.

[54] C. Ding, D. Jia, H. He, B. Guo, and H. Hong, "How organomontmorillonite truly affects the structure and properties of polypropylene," Polymer Testing, vol. 24, no. 1, pp. 94-100, Feb. 2005, https://doi.org/10.1016/j.polymertesting.2004.06.005.

[55] N. el H. Belkham, D. Benachour, and A. Mehamha, "Elaboration and Physico-Chemical Characterization of the Gibbsite $\mathrm{Li}(\mathrm{OH}) 3$ Hybrid Material," Engineering, Technology \& Applied Science Research, vol. 11 , no. 1, pp. 6740-6744, Feb. 2021, https://doi.org/10.48084/ etasr.3988. 